\title{
Influence Mechanism of Lignite and Lignite Semi-coke Addition on Drum Strength of Coke
}

\author{
Tengfei SONG, ${ }^{1)}$ Jianliang ZHANG, ${ }^{1) *}$ Guangwei WANG ${ }^{11}$ Haiyang WANG, ${ }^{1)}$ Runsheng XU ${ }^{21}$ \\ and Qinghai PANG ${ }^{3)}$
}

1) School of Metallurgical and Ecological Engineering, University of Science and Technology Beijing, Beijing, 100083 China.

2) State Key Laboratory of Refractories and Metallurgy, Wuhan University of Science and Technology, Wuhan, 430081 China.

3) School of Materials and Metallurgy, University of Science and Technology Liaoning, Anshan, 114051 China.

(Received on July 27, 2017; accepted on October 12, 2017)

\begin{abstract}
In order to clarify the effect of lignite and lignite semi-coke addition during coking process on the drum strength, I-type drum, thermogravimetric analyzer, SEM and XRD were used to investigate the properties of coke, such as drum strength, coking process, microstructure and crystallite structure. The result showed that because of the dramatically interaction of the volatile matter of lignite with coking coal in the initial coking stage resulting in the increase of uneven degree of macroscopic pores, the drum strength of coke decreased rapidly with the increase of lignite addition ratio. However, when the ratio of lignite semi-coke addition was less than $6 \%$, the stacking height $L c$ value of coke increased and the evolution of macroscopic pores was restrained. By adding lignite semi-coke obtained from carbonization of lignite at $700^{\circ} \mathrm{C}$, the drum strength of coke was improved obviously. Thus, it was promising measure to expand the application scope of lignite in the ironmaking system of blast furnace through carbonization.
\end{abstract}

KEY WORDS: lignite; lignite semi-coke; influence mechanism; drum strength; crystallite structure; pore.

\section{Introduction}

For Chinese ironmaking process, reducing the consumption of blast furnace fuel was the key to relieve the greenhouse gas emission and lower ironmaking cost. ${ }^{1)}$ What's more, with the current increasingly shortage of high quality coking coal, how to reduce the dependence on high quality coking coal was an extremely problem which should to solve for Chinese steel industry. ${ }^{2-5)}$ Many researches had investigated the feasible of using carbon-containing resource to partly replace the coking coal during the coking process. ${ }^{6-9)}$ Nomura et al. ${ }^{10)}$ investigated the effect of plastic addition on the coal caking property and found that the decomposition products of plastics would interacted with the coking coal during the carbonization process resulting in the decrease of coal caking property and coke strength. Mollah et al. ${ }^{11)}$ had tried to produce blast furnace coke using lignite, its commercial products, and briquettes. However, it was found that the produced coke had high compressive strength but the reactivity was too high to be used in a blast furnace. Previous study showed that there still existed in using lignite to produce coke with various difficulties. Though partial replacement of coking coal by cheaper and more abundant coals could bring great economic and environmental benefits, these coals have little bond and coking property. Such as, lignite was porous, low ordered degree of microcrystalline compared to coking coal. If a large number

\footnotetext{
* Corresponding author: E-mail: zhang.jianliang@hotmail.com DOI: http://dx.doi.org/10.2355/isijinternational.ISIJINT-2017-447
}

of lignite was added into the coking coal, it may inevitably degrade the reactivity and strength. ${ }^{11)}$ Therefore, corresponding laboratory experiments are required to explore the feasibility of lignite used as a raw material for coke making.

\section{Experimental Materials and Methods}

\subsection{Preparation of Samples}

Coking coal (labeled as PC) was obtained from a coking plant in Heilongjiang province, China. Lignite (labeled as $\mathrm{HC}$ ) was got from coal mine enterprises near the coking plant. When the lignite was added into the blend coking coal, the solid yield of coke would reduce due to the high volatile content (up to $54.26 \%$ ). In order to avoid the influence of the volatile matter, the lignite was carbonized at $700^{\circ} \mathrm{C}$ holding for $60 \mathrm{~min}$ in $\mathrm{N}_{2}$ gas atmosphere and then cooled to room temperature in the tube furnace. Basic properties of coking coal, lignite and lignite semi-coke were listed in Table 1.

\subsection{Carbonization Method}

The coking coal/lignite mixtures was prepared by adding $2 \%, 4 \% \ldots . .12 \%$ of $-1 \mathrm{~mm}$ lignite to coking coal and was mixed together for $20 \mathrm{~min}$. The mixture samples were labeled as $\mathrm{HC}-2, \ldots \ldots, \mathrm{HC}-12$ and then were put into graphite crucible $(\varphi 20 \mathrm{~mm}, \mathrm{~L} 100 \mathrm{~mm})$. A cylindrical iron was inserted into the graphite crucible to provide about $6 \mathrm{kPa}$ pressure on the mixture sample as shown in Fig. 1. The graphite crucible was put into muffle furnace to be heated to $500^{\circ} \mathrm{C}$ at the rate of $10^{\circ} \mathrm{C} / \mathrm{min}$ and to $950^{\circ} \mathrm{C}$ at the rate of 
Table 1. Basic property of three samples.

\begin{tabular}{|c|c|c|c|c|c|c|c|}
\hline Sample & Thickness of adhesive layer, Y/mm & Caking index, G/\% & Range of fluidity, ${ }^{\circ} \mathrm{C}$ & $\mathrm{Sd}$ & $\mathrm{Vd}$ & Ad & $\mathrm{FCd}$ \\
\hline Coking coal (PC) & 13.2 & 85.0 & $385-450^{\circ} \mathrm{C}$ & 0.41 & 31.01 & 9.85 & 59.14 \\
\hline Lignite (HC) & - & - & - & 0.13 & 54.26 & 8.52 & 37.22 \\
\hline Lignite semi-coke (BC) & - & - & - & 0.23 & 7.01 & 17.28 & 75.71 \\
\hline
\end{tabular}

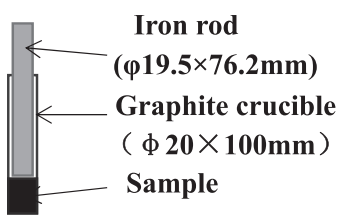

Fig. 1. Diagram of graphite crucible.

$5^{\circ} \mathrm{C} / \mathrm{min}$ in $\mathrm{N}_{2}$ gas atmosphere. The temperature was kept at $950^{\circ} \mathrm{C}$ for $1 \mathrm{~h}$ and then cooled to room temperature in the tube furnace. The addition ratio of lignite semi-coke and experimental process were the same with the lignite and the mixture samples were labelled as BC-2, BC-4.....BC-12.

\subsection{Coke Strength Test}

In order to reveal the effect of lignite/semi-coke addition on the drum strength of coke, the drum strength was measured by using the I-type tumbler tester $(\varphi 130 \mathrm{~mm}, \mathrm{~L} 700 \mathrm{~mm})$. The coke sample was placed into the tumbler, and the rotation speed was set to $20 \mathrm{r} / \mathrm{min}$ for $30 \mathrm{~min}$. The coke sample was taken out from the tumbler every 5 minutes and the particle above $1 \mathrm{~mm}$ was weighed. After weighed, the sample with the particle size of more than $1 \mathrm{~mm}$ was put into the tumbler again. The strength index which was used to revalue the coke strength was calculated as follows: ${ }^{8)}$

$$
\mathrm{TI}_{+1}=\mathrm{W}_{1} / \mathrm{W} * 100
$$

Where $\mathrm{TI}_{+1}$ was the coke drum strength index, \%; $\mathrm{W}_{1}$ and $\mathrm{W}$ were the weight of sample with the particle size of more than $1 \mathrm{~mm}$ and the initial coke sample, g.

\subsection{Thermogravimetric Analysis}

The weight loss of three samples (HC, BC and PC) with temperature increasing was recorded by thermogravimetric analyzer in order to investigate the performance of weight loss in the coking process. About $5 \pm 0.1 \mathrm{mg}$ of sample with a size of $<74 \mu \mathrm{m}$ was heated from room temperature to $1200^{\circ} \mathrm{C}$ at a rate of $3^{\circ} \mathrm{C} / \mathrm{min}$ in $\mathrm{N}_{2}$ gas atmosphere with the flow rate of $100 \mathrm{ml} / \mathrm{min}$. Using the same experimental methods, the weight loss of mixture samples and interaction characteristics between different samples in mixture were also studied. The thermogravimetric analysis was repeated at least three times until the final result was ascertained.

\subsection{Macroscopic Pore Distribution}

To determine the reason of the decrease of $\mathrm{TI}_{+1}$, scanning electron microscope (SEM) was applied to study the effect of $\mathrm{HC}$ and $\mathrm{BC}$ addition on morphology.

The macroscopic pore distribution of coke was evaluated by analyzing the SEM micrographs of the cross section of a coke sample. It should be pointed out that after binarized using image analysis software, the macroscopic pore of coke was labelled black and the pore wall was labelled white for contrast. The scale of SEM image was up to $2 \mathrm{~mm}$, as shown

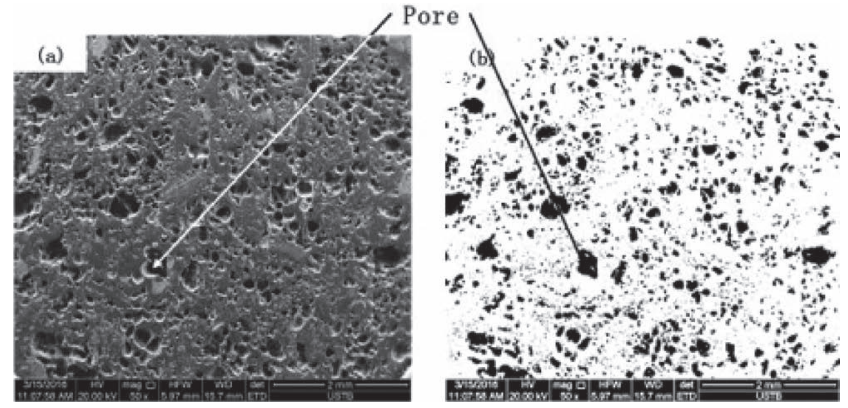

Fig. 2. Example of the macrostructure image binarized.

in Fig. 2. It was believed that over $25 \%$ of the cross section of coke sample had been analyzed, and there was hardly any difference observed from the SEM image of the cross section. Thus, the result of the macroscopic pore distribution was reliable.

\section{Results and Discussion}

\subsection{The Effect of Lignite and Lignite Semi-coke Addi- tion on the Drum Strength of Coke}

The Fig. 3 showed the change in coke drum strength with time. Compared with RC, the drum strength decreased with the increase of the addition ratio of $\mathrm{HC}$ or $\mathrm{BC}$. In the case of $\mathrm{HC}$ addition, when the addition ratio was more than $6 \%$, the $\mathrm{TI}_{+1}$ substantially deteriorated with the addition ratio of $\mathrm{HC}$. Furthermore, after the first $5 \mathrm{~min}$ drum test, the coke had been completely pulverized at the ratio of more than $10 \%$. On the other hand, different from the coke of $\mathrm{HC}$ addition, the $\mathrm{TI}_{+1}$ of the coke of $\mathrm{BC}$ addition was equal to or even higher than that of $\mathrm{RC}$ at the ratio of less than $6 \%$. And then, the $\mathrm{TI}_{+1}$ of the coke of $\mathrm{BC}$ addition decreased along with the increase of the ratio of $\mathrm{BC}$ addition. The above results testified that there was difference between the effect of $\mathrm{HC}$ and $\mathrm{BC}$ addition on the degradation and mechanism of coke drum strength.

The $\mathrm{TI}_{+1}$ of coke depended on both the reasonable mix of different kinds of coals and the pore distribution of coke. ${ }^{12)}$ In order to explore the effect mechanism of $\mathrm{HC}$ and $\mathrm{BC}$ addition on the coke drum strength, the reasonable mix of coals, pore structure, macroscopic pore distribution and microcrystalline structure had been in-depth studied in follow.

\subsection{Thermogravimetric Analysis}

The weight loss rate of three kinds of sample was showed in Fig. 4. The arrow in the Fig. 4 represents the range of fluidity, which was the initial softening temperature and the solidification temperature measured by Gieseler plastometer. That was, the initial temperature of $\mathrm{PC}$ was $385^{\circ} \mathrm{C}$ and the solidification temperature was $480^{\circ} \mathrm{C}$. As we all known, lignite, low-rank coal and lower metamorphic grade, con- 
tained a lot of activity stronger methyl, methylene and heteroatoms like oxygen, which was very easily decomposed. ${ }^{13)}$ Thus, lignite can be decomposed at lower temperature, and the temperature of the maximum weight loss rate was $400^{\circ} \mathrm{C}$. Because of $\mathrm{BC}$ was produced at $700^{\circ} \mathrm{C}$ for $30 \mathrm{~min}$, the weight loss was not obvious during the temperature heating. Meanwhile, the temperature of the maximum weight loss rate was $450^{\circ} \mathrm{C}$ for $\mathrm{PC}$.

As we can see from the Fig. 4, the temperature of the maximum weight loss rate for $\mathrm{HC}$ located right in the plastic temperature interval range of $\mathrm{PC}$. The interaction effect of the products derived from $\mathrm{HC}$ decomposition and $\mathrm{PC}$ may have an important influence on the properties of coke. It was known that the HC started to shrink due to the release of the thermally decomposed products, and the voids and pores were inevitably formed between the PC particle, which continued to develop with the temperature rising. Though the voids and pore could be filled by the free expansion of $\mathrm{PC}$ to some extent at the softening and melting temperature,
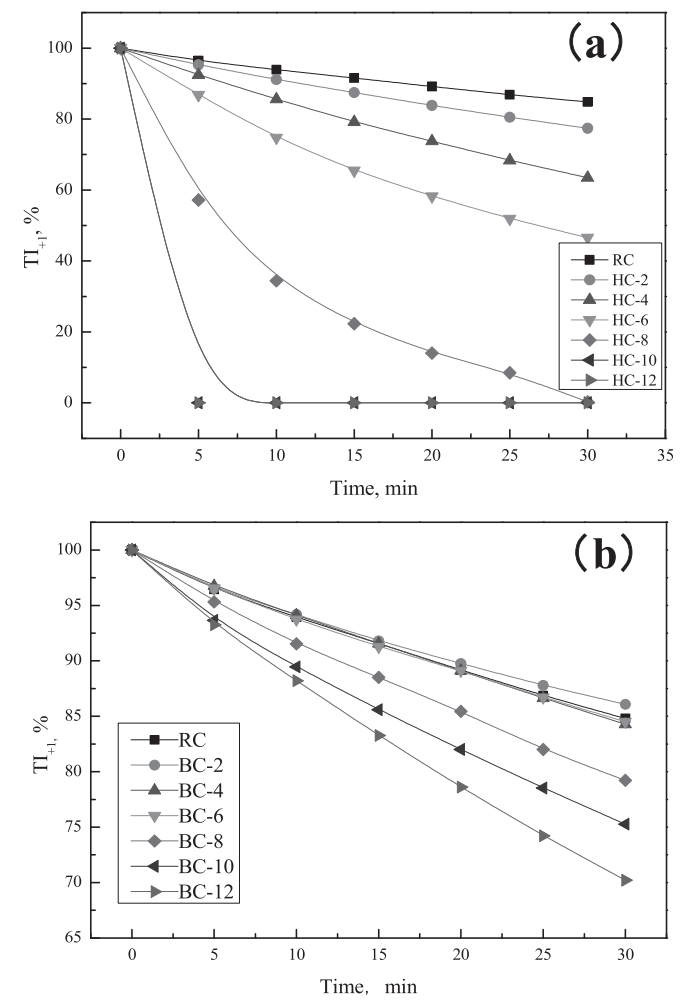

Fig. 3. Change of the $\mathrm{TI}_{+1}$ with time, $\mathrm{a}: \mathrm{HC}+\mathrm{PC}, \mathrm{b}: \mathrm{BC}+\mathrm{PC}$.

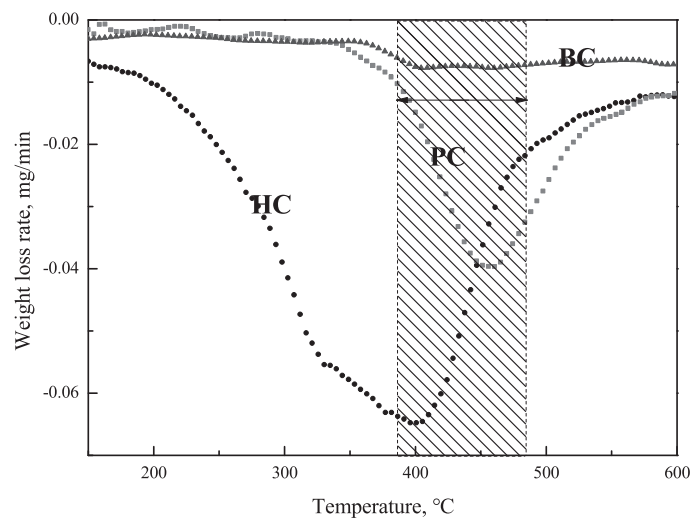

Fig. 4. Weight loss rate of three samples. the macromolecular structure derived from the PC decomposition was prematurely stabled by the radical derived from HC. ${ }^{14)}$ Simultaneously, heteroepoxide in the thermally decomposition product of $\mathrm{HC}$ had a negative influence on the thermoplastic properties of PC in the coking process. ${ }^{15}$ ) From above, it suggested that the HC inhibited the adhesion between $\mathrm{PC}$ particles. The change in weight loss rate of $\mathrm{BC}$ was less than that of $\mathrm{HC}$ products derived from $\mathrm{BC}$ decomposition. It meant that $\mathrm{BC}$ generated fewer thermally decomposition products in the coking process and the interaction between the products derived from BC and PC had little influence on the properties of coke. The $\mathrm{BC}$ sample obtained from carbonization acted as a role of leaning agent like lean coal in the coking process. ${ }^{16-18)}$

The weight loss curves of $\mathrm{HC}, \mathrm{BC}, \mathrm{PC}$ and mixture sample were shown in Fig. 5. The calculated value of weight loss for mixture sample was defined as followed: the calculated value $=$ (the weight loss rate of $\mathrm{HC} / \mathrm{BC}$ at a certain temperature) $\times 0.06+$ (the weight loss rate of $\mathrm{PC}$ at the same temperature) $\times 0.94$.

As shown in Fig. 5(a), the calculated value of mixture sample was more than the measured value in the drastic decomposition temperature range of $200-450^{\circ} \mathrm{C}$ for $\mathrm{HC}-6$. In the case of sample obtained from mixing $\mathrm{BC}$ with $\mathrm{PC}$, the calculated value of mixture sample was also more than the measured value in the initial stage of decomposition of $\mathrm{BC}$ at $400^{\circ} \mathrm{C}$, as shown in Fig. 5(b). It indicated that there was definitely interaction between the $\mathrm{HC} / \mathrm{BC}$ and $\mathrm{PC}$ in the coking process.

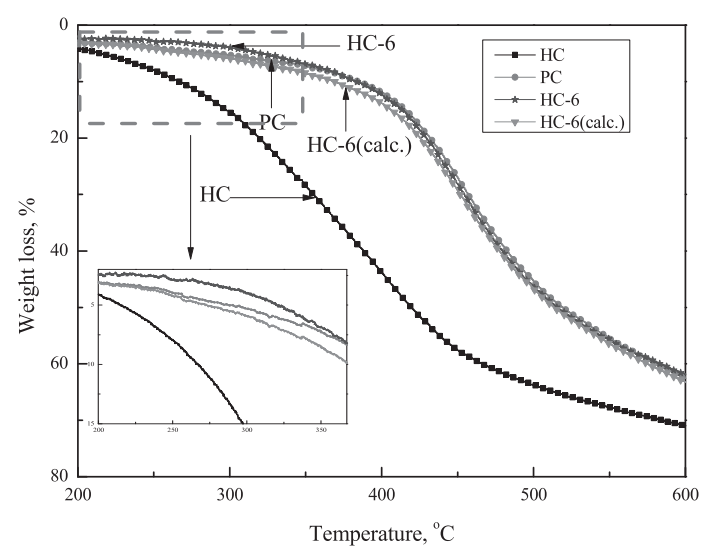

(a)

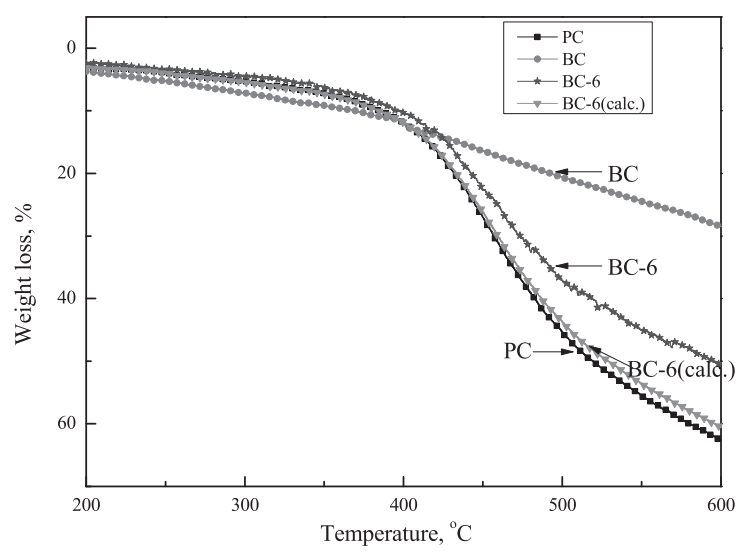

(b)

Fig. 5. Thermogravimetric analysis of samples. 


\subsection{Evolution of Macroscopic Pores}

The SEM images of coke were shown in Fig. 6. As seen in Figs. 6(a) and 6(b), the reference coke had a uniform pore structure, less difference in size and its surface are relatively flat. However, a number of larger pore appeared and the pore wall became thinner in the cross section of HC-6, resulting in the formation of wall-thin pore just like honeycomb, as demonstrated in Fig. 6(d). As a result of uneven pore structure, it would accelerate pulverization of coke and degrade the coke strength seriously. In contrast, the pore distribution of BC-6 was greatly close to that of the reference coke, as shown in Figs. 6(e) and 6(f). It could be concluded that the mechanism of the effect of $\mathrm{BC}$ on the coke strength was different from that of HC.

It was well known that the coke drum strength deeply depended on the macroscopic pores distribution, especially the uneven degree (the ratio of the maximum and minimum of the pore diameter) ${ }^{19)}$ in the paper it was defined as the ratio of the pore area. In general, the bigger uneven degree was, the lower the coke drum strength was. Figure 7 showed the macroscopic pores image binarized using image analyzing software. The total area fraction of macroscopic pores in the cross section of coke increased with the increasing ratio of $\mathrm{HC} / \mathrm{BC}$ addition. In comparison with reference coke, when the addition ratio of $\mathrm{HC}$ was more than $4 \%$, the area fraction of pores with the area fraction of more than $0.1 \mathrm{~mm}^{2}$ and less than $0.01 \mathrm{~mm}^{2}$ increased. It suggested that the uneven degree increased when the addition ratio was more than 4\%. As shown in Figs. 3(a) and 7(a), we could see the coke drum strength decreased along with the increase of the uneven degree, this results was the same to
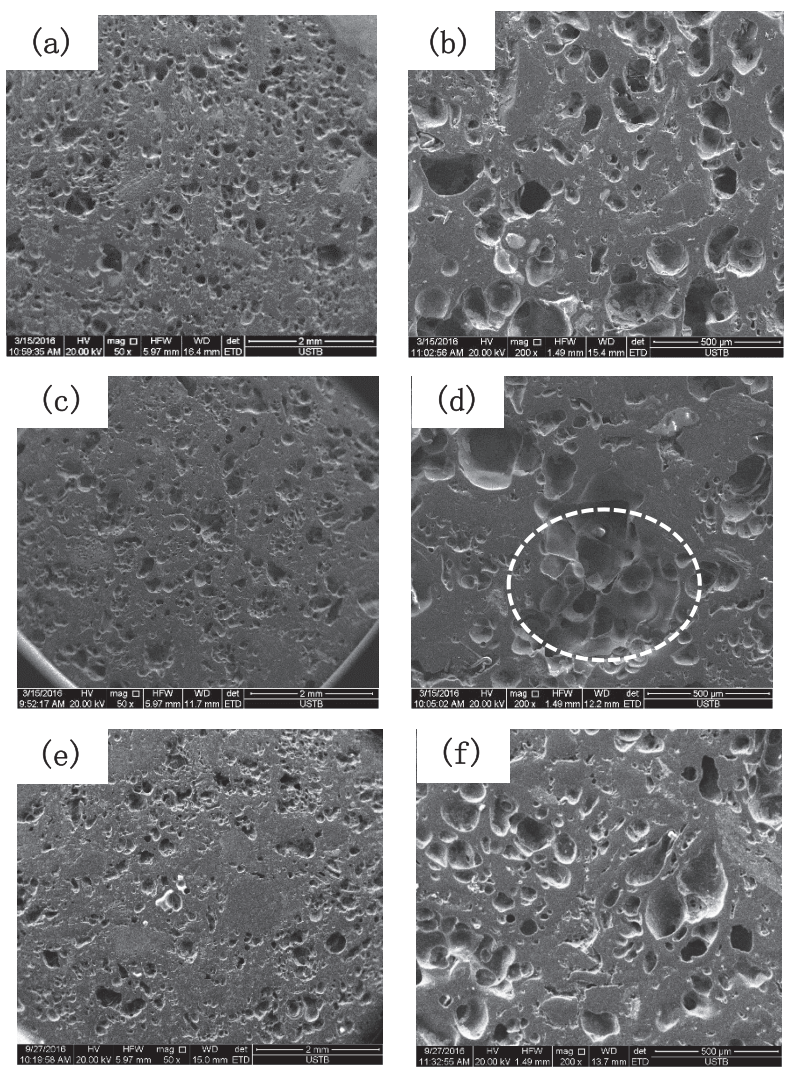

Fig. 6. The SEM images of coke, (a, b): PC (without HC/BC additon); (c, d): HC-6; (e, f): BC-6. the previous results. ${ }^{19)}$

As showed in Fig. 7(b), the area fraction of macroscopic pores increased with the addition ratio of $\mathrm{BC}$. However, the pore more than $0.1 \mathrm{~mm}^{2}$ disappeared and the pore whose area was $0.01-0.1 \mathrm{~mm}^{2}$ and less than $0.01 \mathrm{~mm}^{2}$ increased when the $\mathrm{BC}$ was added to the $\mathrm{PC}$, which indicated that the change of uneven degree was not obvious. Compared with the area fraction of original coke, the pore area fraction of coke with the $\mathrm{BC}$ addition ratio of $2-6 \%$ was less than that of original coke. According with the above section 3.1, the coke drum strength firstly increased and then decreased with the addition ratio of $\mathrm{BC}$. Thus, it can be concluded that a moderate amount of leaning agent had a role in improving the coke drum strength. ${ }^{20)}$ Since the $\mathrm{BC}$ obtained from carbonization at $700^{\circ} \mathrm{C}$ still contained a certain amount of volatile matter, in order to ensure the $\mathrm{BC}$ promoting the formation of the pore wall and improve the quality of coke, the further research would focus on how to choose the appropriate carbonization temperature of $\mathrm{HC}$.

\subsection{The Influence Mechanism of Lignite and Lignite Semi-coke on Drum Strength of Coke}

Through above analysis, it could be found that the influence mechanism of $\mathrm{HC} / \mathrm{BC}$ addition on coke drum strength was different, mainly for the following reasons:

As a result of the development of the macroscopic pores for coke with lignite addition, the area fraction of more than $0.1 \mathrm{~mm}^{2}$ and less than $0.01 \mathrm{~mm}^{2}$ increased greatly leading to the decrease of the coke drum strength accordingly. When

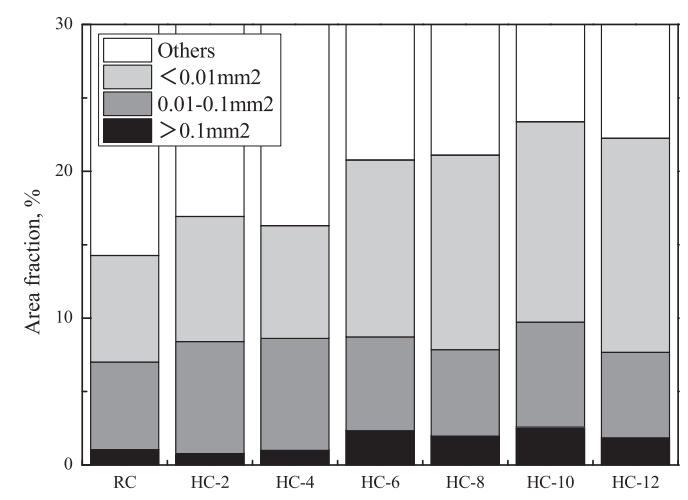

(a)

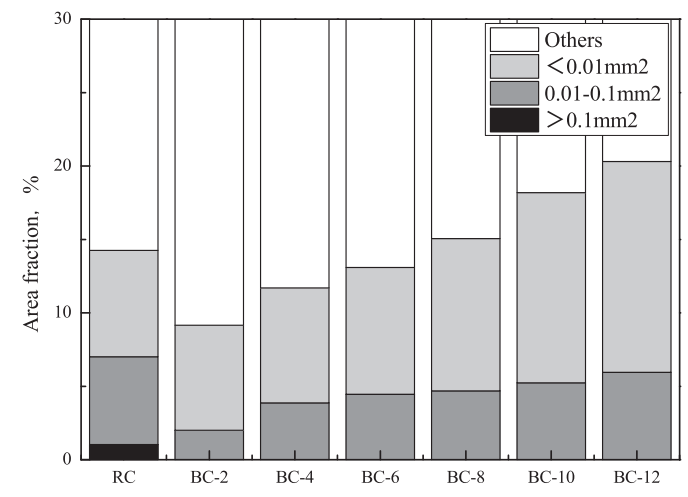

(b)

Fig. 7. Effect of lignite and lignite semi-coke addition on the area fraction of coal particles. 
polyethylene or vinyl chloride was co-carbonized with coking coal, the gas obtained from the decomposition of polyethylene at the low temperature resulted in free dilatation of coking coal at the initial reaction time, and then a number of pores and voids was gradually formed due to the high permeability. ${ }^{10)}$ Meanwhile, with the temperature rising, the macromolecular structure and decomposed gas started to dramatically spill out from the softening and melting coal attributed to the high permeability and then restrained the formation of colloid. The cohesiveness between coal particles decreased, unavoidably. The volatile matter of lignite used in this experiment was up to $52 \%$, and the temperature interval of the thermal decomposition for lignite was overlapped with that of the fluidity of coking coal. Hence, the formation of large pores in the initial stage of lignite decomposition and the development of fine pores due to the higher permeability of the coking coal were both important factors in deteriorating coke drum strength, as demonstrated in Fig. 8.

Afterwards, as we all known that there was a certain amount of monomers, dimers, trimers and polymer radicals generated in the process of lignite thermally decomposition. ${ }^{21)}$ In the temperature range of lignite decomposition, the coking coal also started to release the macromolecular structure accordingly. ${ }^{22,23)}$ The free radical derived from lignite decomposition would abstract hydrogen from coking coal and hence inhibit the caking property of coking coal particle. From a macroscopic view, the drum strength of coke decreased rapidly with the addition ratio of lignite more than $4 \%$.

Lignite semi-coke was made from lignite carbonization at the temperature of more than the temperature region of fluidity of coking coal, and volatile matter was just $7 \%$ like anthracite. Fang et $a l .{ }^{24)}$ found that anthracite enhanced the stacking height of coke microcrystalline structure, promoting the growth of microcrystalline structure. However, microcrystalline structure was investigated at a certain ratio of anthracite addition. Figure 9 showed the X-ray diffraction pattern of cokes with lignite and lignite semi-coke addition. The characteristic (002) peak indicated the stack spacing of aromatic ring layers, graphite-like structures, and the intensity of the (002) peak decreased with the increasing ratio of lignite or lignite semi-coke addition. Through this result derived by Scherrer, ${ }^{25)}$ we could see that the stacking height $(L c)$ of coke increased with the increasing ratio of lignite/lignite semi-coke addition within $6 \%$ and that decreased at the ratio of more than $6 \%$, as demonstrated in Fig. 10.

Microcrystalline structure parameters were commonly used to determine the coke reactivity, ${ }^{2,26)}$ volatile matter and aromaticity of pulverized coal qualitatively or quantita-

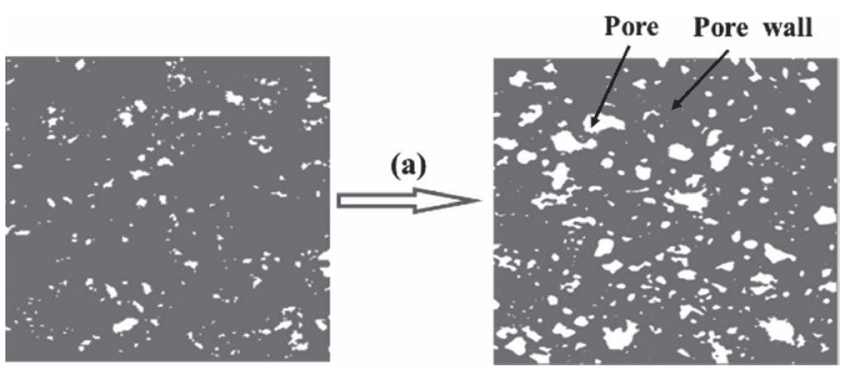

Fig. 8. A schematic representation for the degradation mechanisms of lignite on coke. tively. ${ }^{27)}$ The relationship between stacking height $(L c)$ and drum strength of coke was shown in Fig. 11. The linear relationship between the stacking height and the drum strength for coke with lignite addition was not so obvious, and the fitting degree was only 0.72 . However, the stacking height (Lc) had a good linear relationship with the drum strength of coke with the lignite semi-coke addition, as shown in Fig. 11 (b) and the fitting degree was 0.94 . It could obtain the result that the decrease of stacking height $(L c)$ may increase the distance between micro graphite crystals leading to the improving of the degradation resistance to external force for coke with lignite semi-coke addition, as shown in Fig. 12. In other words, the effect of lignite semi-coke addition on the coke drum strength greatly depended on the


Fig. 9. X-ray diffraction pattern of coke, a: $\mathrm{HC}+\mathrm{PC}, \mathrm{b}$ : $\mathrm{BC}+\mathrm{PC}$.

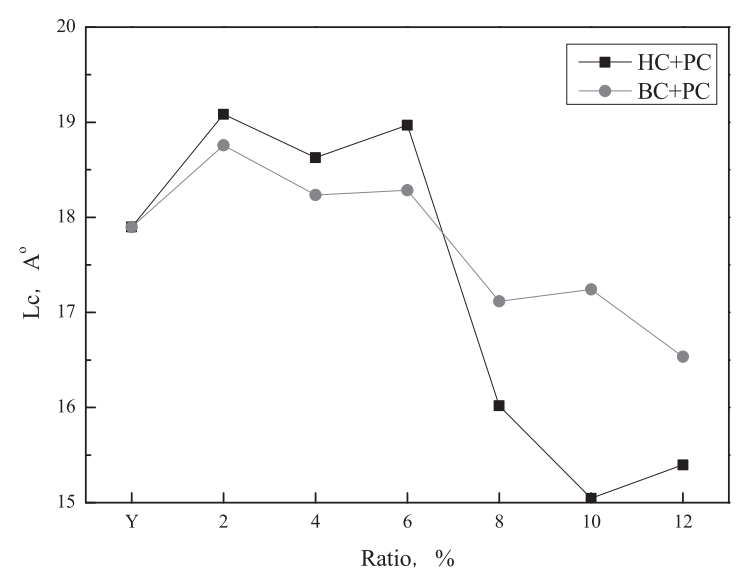

Fig. 10. Stacking height $(L c)$ of coke with the lignite/lignite semicoke blend ratio. 

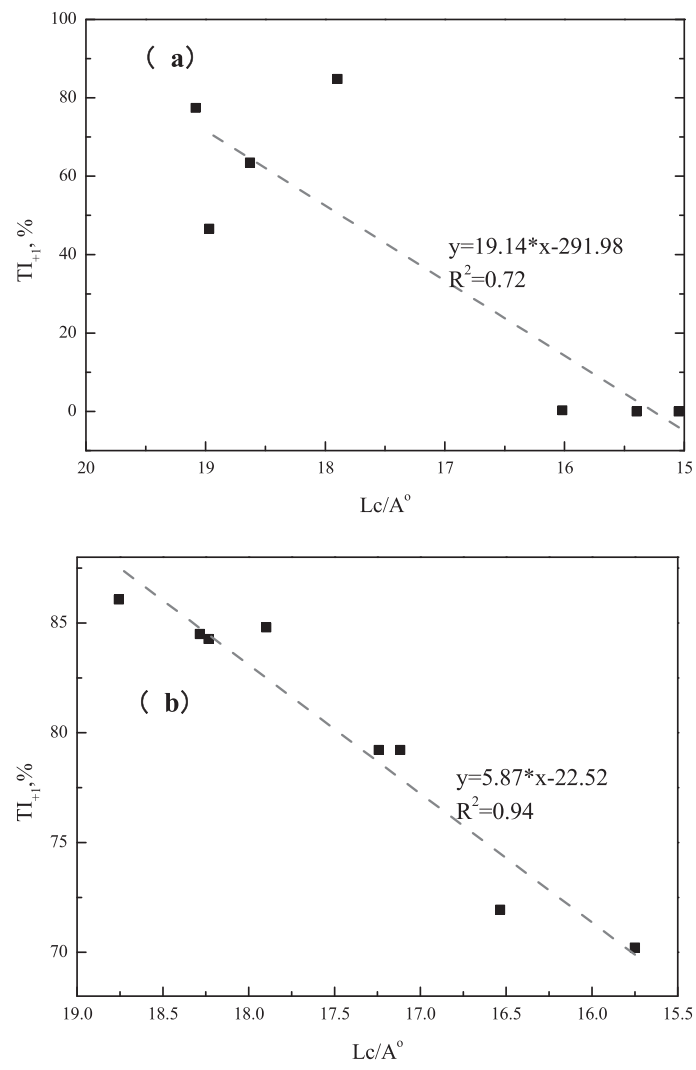

Fig. 11. Relationship between stacking height $(L \mathrm{c})$ and drum strength, a: $\mathrm{HC}+\mathrm{PC}, \mathrm{b}: \mathrm{BC}+\mathrm{PC}$.

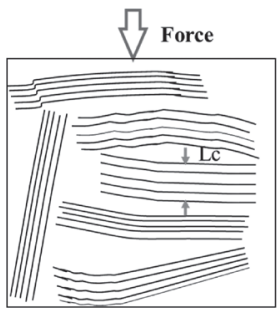

Before reaction



After reaction
Fig. 12. A schematic representation for the degradation mechanisms of lignite semi-coke on coke.

ordered crystal structure. Besides, the drum strength could be predicted according to the stacking height of coke with lignite semi-coke addition. It was necessary to point out that the particle size of lignite semi-coke in this study was less than $1 \mathrm{~mm}$, further study should focus on the effect of particle size on the coke drum strength and microcrystalline structure.

\section{Conclusions}

(1) The dramatically interaction of the decomposition products of lignite with coking coal resulted in the decrease of the coke drum strength, it should reduce the ratio of lignite addition as less as possible. As a result of the lower interaction between lignite semi-coke and coking coal, the drum strength of coke with the lignite semi-coke addition was higher than that of original coke at the addition ratio of less than $6 \%$.

(2) The temperature interval of the thermal decompo- sition for lignite was overlapped with that of the fluidity of coking coal and the decomposition products abstracted the hydrogen derived from coking coal leading to the decrease of caking property. Then, the uneven degree of pore increased, finally resulting in the decrease of the coke drum strength.

(3) The stacking height of coke with lignite and lignite semi-coke addition firstly increased and then decreased. The stacking height $(L \mathrm{c})$ had a good linear relationship with the drum strength of coke with the lignite semi-coke addition. In the case of coke with lignite semi-coke addition, the drum strength could be predicted according to the stacking height.

(4) The lignite semi-coke could promote the growth of stacking height and restrain the formation of bigger pores, finally to increase the coke drum strength at the addition ratio of less than $6 \%$.

\section{Acknowledgements}

This work was financially supported by the Beijing Municipal Science \& Technology Commission of China (Z161100002716017).

\section{REFERENCES}

1) T. Ariyama, R. Murai, J. Ishii and M. Sato: ISIJ Int., 45 (2005), 1371.

2) K. J. Li, R. Khanna, J. J. Zhang, Z. J. Liu, V. Sahajwalla, T. J. Yang and D. Kong: Fuel, 133 (2014), 194.

3) M. Lundgren, R. Khanna, L. S. Ökvist, V. Sahajwalla and B. Björkman: Metall. Mater. Trans. B, 45 (2014), 603.

4) R. S. Xu, J. J. Zhang, G. G. Wang, H. B. Zuo, Z. J. Liu, K. X. Jiao, Y. X. Liu and K. J. Li: Metall. Mater. Trans. B, 47 (2016), 2535.

5) R. S. Xu, J. J. Zhang, G. G. Wang, H. B. Zuo, P. C. Li, H. Y. Wang, H. Lin and S. Y. Liu: J. Therm. Anal. Calorim., 123 (2016), 773.

6) R. S. Higgins, G. L. Kennedy and D. G. Evans: Aust. Inst. Min. Metall. Proc., (1960), No. 195, 103.

7) M. A. Diez and A. G. Borrego: Fuel, 113 (2013), 59.

8) Y. Ueki, Y. Nunome, R. Yoshiie, I. Naruse, Y. Nishibata and S. Aizawa: ISIJ Int., 54 (2014), 2454

9) M. A. Diez, R. Alvarez and J. L. G. Cimadevilla: Fuel, 114 (2013), 216.

10) S. Nomura, K. Kato, T. Nakagawa and I. Komaki: Fuel, 82 (2003), 1775 .

11) M. M. Mollah, W. R. Jackson, M. Marshall and A. L. Chaffee: Fuel, 148 (2015), 104

12) S. Miura and P. L. Silveston: Carbon, 18 (1980), 93

13) H. J. Song, G. R. Liu and J. H. Wu: Energy Convers. Manag., 126 (2016), 1037.

14) S. Nomura, K. Kato, T. Nakagawa and I. Komaki: Fuel, 82 (2003), 1775 .

15) A. Grint, S. Mehani, M. Trewhella and M. J. Crook: Fuel, 64 (1985), 1355.

16) T. Kanai, Y. Yamazaki, X. Zhang, A. Uchida, Y. Saito, M. Shoji, H. Aoki, S. Nomura, Y. Kubota, H. Hayashizaki and S. Miyashita: J. Therm. Sci. Technol., 7 (2012), No. 2, 351.

17) C. H. Pen: Coal Chem. Indu., 33 (2005), 47.

18) J. G. Wang, J. H. Zhou, Y. M. Hu, C. H. Peng and Z. W. Zhang: Fuel Chem. Processe., 38 (2007), 1 (in Chinese).

19) Y. N. Fu: Blast Furnace Coke first ed. Metallurgical Industry Press, Beijing, (1995).

20) G. F. Xue, R. Xiang, P. Chen and X. H. Zhang: J. Wuhan Univ. Sci. Technol., 32 (2009), 418.

21) L. J. Jin, X. Y. Bai, Y. Li and C. Dong: Fuel Process. Technol., 147 (2016), 41.

22) F. Fortin and J. N. Rouzaud: Fuel, 73 (1994), 795

23) M. M. Maroto-Valer, C. J. Atkinson, R. R. Willmers and C. E. Snape: Energy Fuel., 12 (1998), 833.

24) Y. Z. Fang, Y. P. Cao, M. L. Jin, J. H. Yang and Z. F. Qian: Iron Steel, 41 (2006), 16.

25) L. Lu, V. Sahajwalla, C. Kong and D. Harris: Carbon, 39 (2001), 1821.

26) W. Wang, J. Wang, R. S. Xu, Y. Yu, Y. Jin and Z. L. Xue: Fuel Process. Technol., 159 (2017), 118.

27) L. Lua, V. Sahajwalla, C. Kong and D. Harris: Carbon, 39 (2001), 1821. 